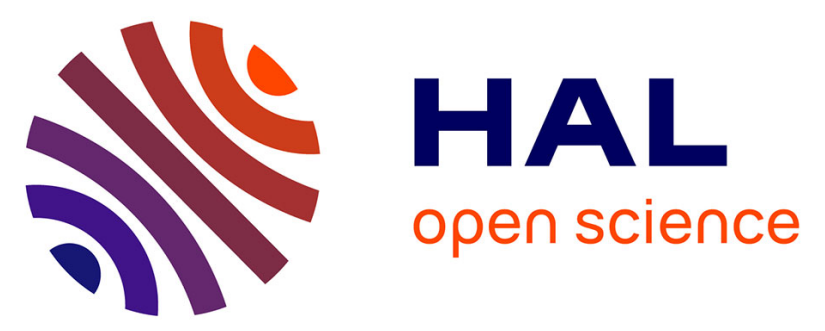

\title{
Activity-Based Discrete Event Simulation of Spatial Production Systems: Application to Fisheries
}

Eric Innocenti, Paul-Antoine Bisgambiglia, Dominique Urbani

\section{To cite this version:}

Eric Innocenti, Paul-Antoine Bisgambiglia, Dominique Urbani. Activity-Based Discrete Event Simulation of Spatial Production Systems: Application to Fisheries. IFIP International Conference on Advances in Production Management Systems (APMS), Sep 2014, Ajaccio, France. pp.240-247, 10.1007/978-3-662-44733-8_30 . hal-01387188

\section{HAL Id: hal-01387188 \\ https://inria.hal.science/hal-01387188}

Submitted on 25 Oct 2016

HAL is a multi-disciplinary open access archive for the deposit and dissemination of scientific research documents, whether they are published or not. The documents may come from teaching and research institutions in France or abroad, or from public or private research centers.
L'archive ouverte pluridisciplinaire HAL, est destinée au dépôt et à la diffusion de documents scientifiques de niveau recherche, publiés ou non, émanant des établissements d'enseignement et de recherche français ou étrangers, des laboratoires publics ou privés. 


\title{
Activity-based Discrete Event Simulation of Spatial Production Systems: application to fisheries
}

\author{
Eric Innocenti, Paul-Antoine Bisgambiglia, Dominique Urbani \\ University of Corsica UCPP, UMR 6134 SPE CNRS, 20250 CORTE FRANCE \\ (eric.innocenti, bisgambiglia, durbani) @univ-corse.fr
}

\begin{abstract}
In this paper, we present a modular and generic object framework using the Discrete EVent system Simulation Specification $(D E V S)$ and the activity concept. We plan to simulate coastal fishery policies in the aim of improving harvesting and the management of fisheries.
\end{abstract}

Keywords: Spatial Production Systems, Cellular Automata Model, DEVS.

\section{$1 \quad$ Introduction}

Application of long-term effective policies in natural production systems needs relevant decision-making indicators and quantitative assessments. This issue is critical in fisheries management facing the decline of world productivity due to pressures from overfishing, habitat change, pollution, and climate change [1]. It is possible to develop software tools dedicated to the election of strategies for sustainable fisheries management (fishing gear regulation, stock rebuilding projects, etc.) [2] - [4]. This work remains part of a computer tool designed to help fishery managers. The main goal is to assist in the definition of a responsible fishing policy in Corsica. We discuss the opportunity to develop a modular framework using the Discrete EVent system Specification formalism (DEVS) and the activity concept. We plan to develop software to simulate coastal fishery policies to improve the management of resources. We use a Cellular Automata Model (CAM) for spatial representation and taking into account the activity concept [5]-[8]. CAM are usually considered as an aggregation of discrete components with local interactions. The model of fish population growth is inspired by the literature [19], [20], and spatially explained with a CAM. The techniques developed are discussed, including challenges, perspectives and limitations. Section 2 reminds the theoretical concepts and section 3 details the software framework before presenting an illustrative application (section 4). The last section before the discussion and concluding remarks gives our simulation results, we want to show that when CAM are jointly used with the DEVS formalism [9] and the activity concept, both the model and the simulator objects efficiently exploit the numerous spatial components.

adfa, p. 1, 2011.

(C) Springer-Verlag Berlin Heidelberg 2011 


\section{Backgrounds}

\subsection{Cellular automata modelling}

Cellular Automata Model $(C A M)$ are an evolved form of von Neumman's Cellular Automata $(C A)$ [8], [9]. These computational models are well suited to capture essential features of spatial systems in which large-scale behaviour arises from the collective effect of a great number of locally interacting simple components. As CAM inherit their basic characteristics from $C A$, they get the benefit of emerging phenomena. From a simple and deterministic local rule, $C A M$ can generate a surprisingly complex global behaviour. The spatial interactions between cells are key elements of such models. At each time step, a cell changes state according to the local rule linked to its neighbourhood. The successive states of the cells follow a state trajectory, in the discrete time base. The state of the $C A M$ is the aggregation of the cell states. Over the last years, the study of IT implementation of $C A M$ considerably increased [11-15]. The determination of active components in this kind of model is also an essential aspect to improve the computing model elegance and to guarantee acceptable simulation times. In the next subsection we give more information on the activity concept. .

\subsection{Activity concept}

The activity concept is usually formulated as a measure of change in system behaviour [9], and is used to concentrate computations on the high rates of change [14], [15]. The activity in a $C A M$ is determined by the measure of the active cells, i.e. by the set of cells that can change state between two global state transitions. The activity is measured at the highest level of the hierarchy, i.e., at the global level of the CAM in a set of active cells. The local level informs the global level on the model activity: (1) at time $t$, the simulator browses the active cells and executes their transition functions $\delta_{\text {int }}$ (transition phase); (2) at the same time, the neighbouring inactive cells are tested in order to determine if they can become active at $t+1$ (propagation phase). This step is called and relies on the propagation rule. The inactive neighbouring cells of active cells are placed as active if they can become active at $t+1$. Whatever the size of the $C A M$ considered, computations only depend on activity, thus the formulation of the propagation rule is a key element to enhance simulation times.

\subsection{DEVS formalism}

$D E V S$ formalism was introduced in [8] as a rigorous basis for the compositional modelling and simulation of discrete event systems. A DEVS model is either an Atomic $(A M)$ or a Coupled $(C M)$ model. An $A M$ is a structure: $\left\langle X, Y, S, \delta_{e x t}, \delta_{i n t}, \lambda, t_{a}\right\rangle$ with $X$ the set of external events, $Y$ the set of output events, $S$ the set of sequential states, $\delta_{\text {ext }}$ : 
$Q \times X \rightarrow S$ the external state transition function, where $Q=\left\{(s, e) \mid s\right.$ in $S, O \leq e \leq t_{a}(s)$ and $e$ is the elapsed time since the last state transition; $\delta_{\text {int }} S \rightarrow S$ the internal state transition function; $\lambda: S \rightarrow Y$ the output function and $t_{a}: S \rightarrow R^{+}{ }_{0 \rightarrow \infty}$ the time advance function. The $A M$ describes the behaviour of the system. A $C M$ describes the composition of several DEVS sub-models, i.e $A M$ or $C M$. We have developed our DEVS simulator inspired by pythonDEVS [16] and DEVS-Ruby [17], and in this work we use the DEVS simulator taking into account the activity concept previously described.

\section{Framework}

In this section, we give a brief description of our simulation software. Our approach is not based on Cell-DEVS [18], but on the multi-component concepts [8]. One atomic model aggregates the entire environment.

\subsection{Activity-based Discrete Event Simulation}

The use of the activity concept implies the prediction of next active cells from a simulation procedure based on events. While applying these criteria to the CAM previously described, it is appropriate to use a discrete event system that cause transitions through the triggering of events based on message exchanges. For that, the model is established on the basis of DEVS formalism. The CAM used for the simulation is aggregated in an $A M$. It interacts with the simulator with ports and messages. The perimeter of the active area is updated when an internal event occurs $\left(\delta_{\text {int }}\right)$.

\subsection{Object implementation}

Objects ensure modularity, genericity, and reusability and the DEVS formalism comes with well established discrete event simulation algorithms. The main objects and the interconnections are presented in figure 1 . The left part describes the simulation part, it is conventional in DEVS. The right part shows the encapsulation mechanism of CAM in an atomic model.

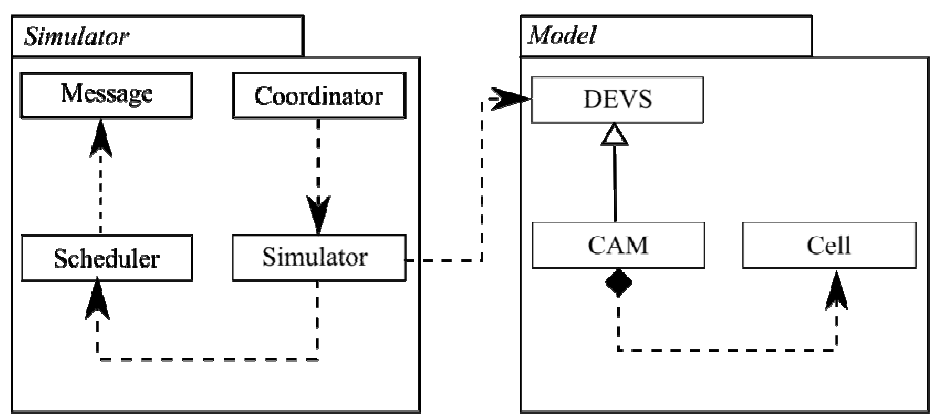

Fig. 1. The CAM and its DEVS objects. 


\section{Illustrative application: Fox model adaptation}

To study the effect of the fishery on biomass and to estimate the Maximum Sustainable Yield (MSY) in each cell, we implement a Fox Surplus-Production Model (SPM) [19], [20]. The $M S Y$ corresponds to the maximum capture that does not exhaust the fish population. SPM models are advantageous as they allow to simply estimate both fish stock and fish rates. Moreover, they collect in the same production model the evolution rules of the biomass, the mortality and population growth. Thus, they only require temporal series of stock abundance indexes that eases their use. The Fox SPM [18] is a particular case of the Pella and Tomlison model [20]. It allows characterising the fish population $x$ according to a set of coefficients, as:

$f\left(x_{t}\right)=\frac{(p+1)}{p} \times r \times x \times\left(1-\left(\frac{x}{K}\right)^{p}\right)(1)$

$f\left(x_{t+1}\right)=x \times(1-\varphi-r * \log (x / K)) \times \varepsilon(2)$

Where $\varphi$ is the fish rate, $\varepsilon$ the environmental variability, $\mathrm{r}$ the population rate, $\mathrm{K}$ the maximum capacity of the environment, $p$ an asymmetric coefficient.

In the Fox's model, $p$ is near 0; this allows getting an asymmetric fish stock evolution. The model grows up to a $K$ maximum constant, and it decreases keeping an asymptotic course. These models are relatively simple and well documented in literature. This model is implemented in each cell of the $C A M$ with $K=90$.

\subsection{SPM Model settings}

The environmental map is composed by reef and fishing areas: the reef areas model the life spaces of the fish. They have a strong attraction capacity as they feed the fish. The attraction coefficient $a C f f$ allows setting the attraction capacity of the cell. The value of $a C f f$ of each cell depends on the distance between the cell and the location of the reef area. The attraction capacity of the cells around the reef areas is randomly calculated at the initialization. The fishing areas are space with fishing production determined by the fishing rate $\varphi$. In the original Fox's model, the fish rate is applied to all the cells of the space. In order to clearly study the effect of fishing, we only apply it to the cells set as fishing areas. During simulation, we apply the transition rule in charge of the fish population evolution, and the propagation rule in charge of the movement of fishes in space (Fig. 2).

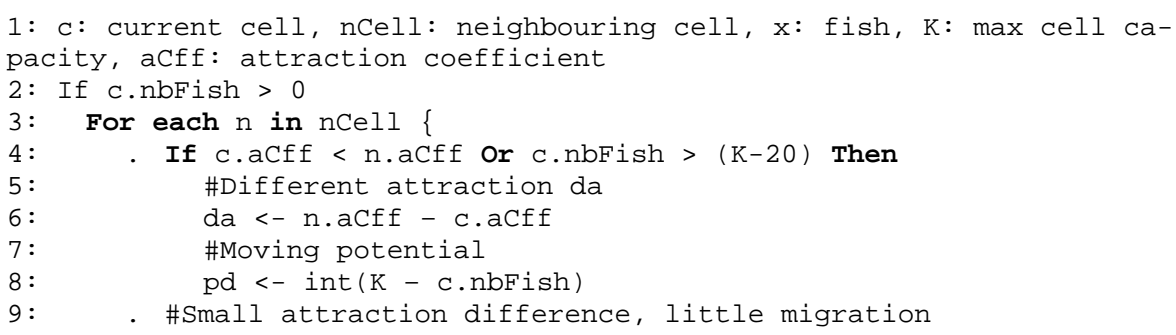




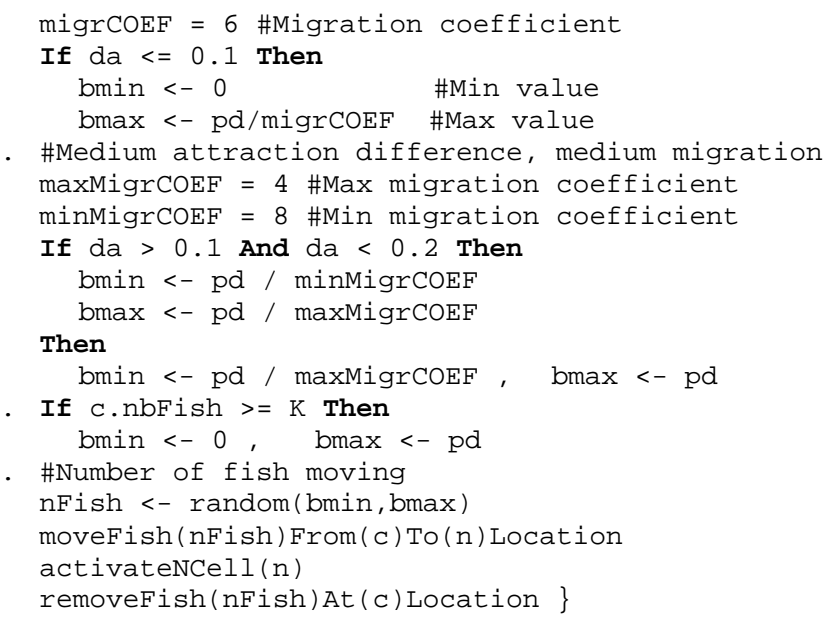

Fig. 2. CAM Propagation phase algorithm.

\subsection{Simulation example}

We compare the fish population evolution in fishing areas and in an area where fishing is prohibited. Thanks to the activity concept we can simulate a domain of 350x 250 cells. We experiment a reef area with maximal attraction (1.0). The attraction around the reef area is randomly determined between 0.5 and 0.9 . These coefficients have been empirically defined. The number of active cells evolves during the simulation process. The main values of the model's coefficients are detailed in table 1.

\begin{tabular}{|l|c|c|c|c|}
\cline { 2 - 5 } \multicolumn{1}{c|}{} & Ocean & Reef-Crown & $\begin{array}{c}\text { Fishing area } \\
(10 \text { cells })\end{array}$ & $\begin{array}{c}\text { Fishing area } \\
t=40(83 \text { cells })\end{array}$ \\
\hline Population growth $r$ & 0.2 & $0.9-0.75$ & 0.9 & 0.9 \\
\hline Cell capacity $K$ & 90 & 90 & 90 & 90 \\
\hline Fish rate $\varphi$ & 0.1 & $0.4-0.45$ & 1 & 2.5 \\
\hline Attraction aCff & 0 & $0.5-1$ & $0.5-1$ & $0.5-1$ \\
\hline
\end{tabular}

Table 1. Model's setting.

The simulation results point out the fish quantities evolution in the simulated time.

\subsection{Results}

The curve presented in Fig. 3 shows the activity of cells. It decreases slightly with a stronger tendency to $t=40$, corresponding to the beginning of overfishing. Trawlers have emptied cells and they have become inactive. 


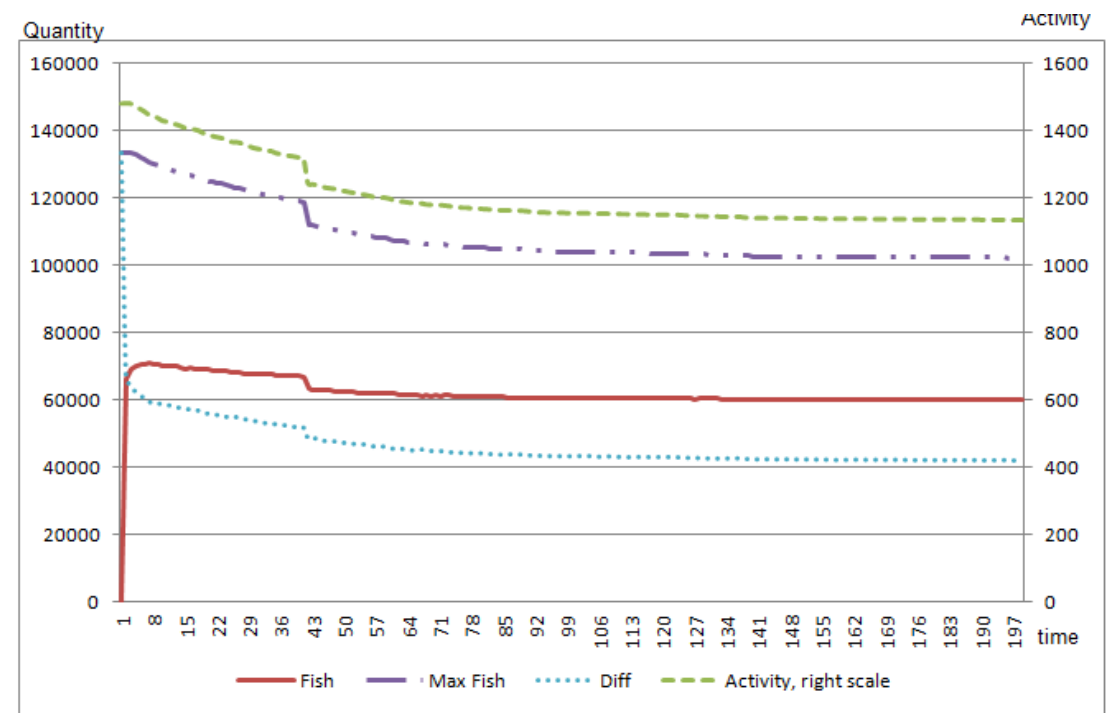

Fig. 3. : Fish quantity and activity evolution. The blue curve represents the evolution of the fish population. The red curve describes the maximum capacity of the environment according of the $\mathrm{K}$ parameter and the number of active cells.

The fish population evolves as the activity level. The activity curve is a good indicator trend of the model.
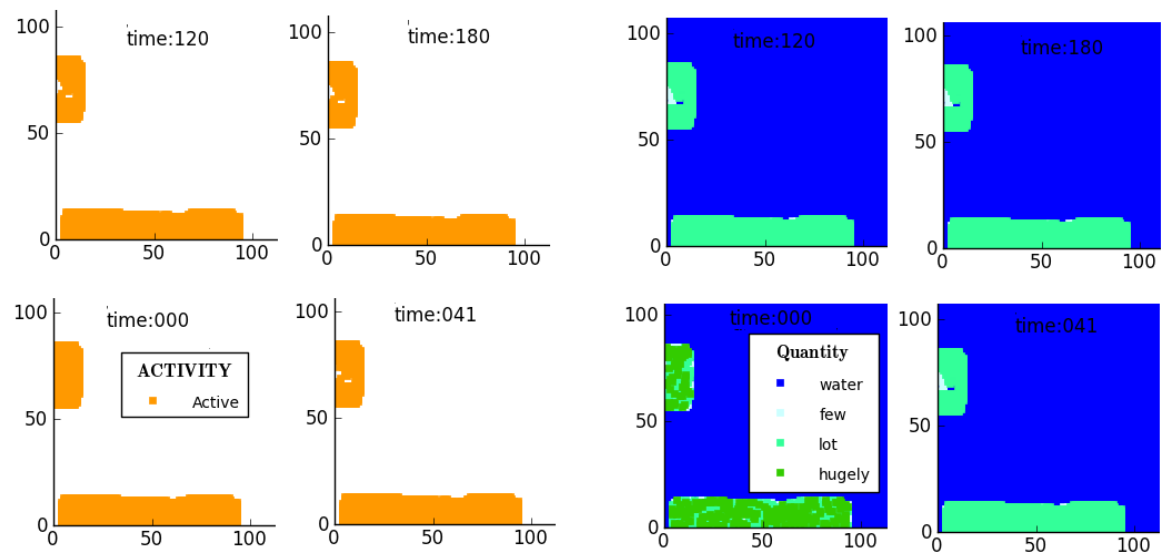

(a)

(b)

Fig. 4. Activity (a) and population (b) evolutions.

Figure 4a represents the evolution of the activity, at $t=0,41,120,180$. Active cells are greatly influenced by the reef areas and their attraction. Figure $4 \mathrm{~b}$ shows the population fish at $0,41,120$, and 180. After initialization, the homogenization of the fish 
population is due to the propagation rule. The fish population comes on the outskirts of the reefs. The results highlight the influence of attractions areas in the development of biomass, and the impact of fishing and overfishing. The activity does not directly increases with the increase of fish quantity, it is quite stable, and clearly shows to $\mathrm{t}=40$ the increase in fishing. A targeted and intensive fishing activity quickly reduces the fish population per cell. To improve the model, we will substitute the fishing areas by agents following the fish population.

\section{Conclusion}

In this paper we described a research approach using the activity concept and the Discrete EVent system Simulation Specification formalism to model the management and harvesting of resources for fisheries. The DEVS formalism is coupled with a $\mathrm{Cel}$ lular Automata Model to efficiently exploit numerous spatial components. With this approach we simulate a complex fishery production system with strong interactions between components evolving in huge spatial areas. Spatial data are generated in a modular and hierarchical way in reasonable computation times. We use our framework to explore the maximum sustainable yield (MSY) and to fix the max sustainable catch in a large fishing area. Using our software framework, decision makers can explore various policies and make choices to improve the management and harvesting of fisheries resources. Using a traditional population growth model from literature [19], we show how our theoretical approach can be used to integrate spatial dynamics, in spite of a huge number of components. Future works will require the integration of the findings and insights of experimental studies. As in [21], we plan also to add an economic model that takes into account the sales of fish and the cost of fuel. We can thus add a propagation rule for trawlers. At the environmental level, we want to integrate the dynamics of biomass (phyto/zooplankton) and currents and finally implement a propagation rule of biomass based on currents.

\section{References}

1. V. Klemas, « Fisheries applications of remote sensing: An overview », Fish. Res., vol. 148, no 0, p. 124 - 136, 2013.

2. Z. Chen, S. Xu, Y. Qiu, Z. Lin, et X. Jia, « Modeling the effects of fishery management and marine protected areas on the Beibu Gulf using spatial ecosystem simulation », Fish. Res., vol. 100, nº 3, p. 222 - 229, 2009.

3. D. Pelletier et S. Mahévas, «Spatially explicit fisheries simulation models for policy evaluation », Fish Fish., vol. 6, n 4, p. 307-349, 2005.

4. B. L. Johnson, « Applying Computer Simulation Models as Learning Tools in Fishery Management », North Am. J. Fish. Manag., vol. 15, n 4, p. 736-747, 1995.

5. E. Innocenti et D. Cancellieri, « Randomizing activity in fire spreading simulations », ITM Web Conf., vol. 1, p. 02003, 2013. 
6. E. Innocenti, A. Muzy, A. Aiello, J.-F. Santucci, et D. R. C. Hill, « Active-DEVS: a computational model for the simulation of forest fire propagation », in Systems, Man and Cybernetics, 2004 IEEE International Conference on, 2004, vol. 2, p. 1857-1863 vol.2.

7. J. von Neumann, «John von Neumann - Collected Works. Volume V: Design of Computers, Theory of Automata and Numerical Analysis », A. H. Taub, Éd. Pergamon Press, 1961, p. 288-328.

8. B. P. Zeigler, H. Praehofer, et T. G. Kim, Theory of Modeling and Simulation: Integrating Discrete Event and Continuous Complex Dynamic Systems. Academic Press, 2000.

9. A. Muzy et D. R C Hill. 2011. «What is new with the activity world view in modeling and simulation? using activity as a unifying guide for modeling and simulation ». In Simulation Conference (WSC), Proceedings of the 2011 Winter, 2882-2894. doi:10.1109/WSC.2011.6147991.

10. A. Santé, M. García, D. Miranda, et R. Crecente, «Cellular automata models for the simulation of real-world urban processes: A review and analysis », Landsc. Urban Plan., vol. 96, no 2, p. 108-122, 2010.

11. J. Podrouzek, «Stochastic Cellular Automata in Dynamic Environmental Modeling: Practical Applications », Electron. Notes Theor. Comput. Sci., vol. 252, no 0, p. 143 - 156, 2009.

12. V. Guinot, «Modelling using stochastic, finite state cellular automata: rule inference from continuum models », Appl. Math. Model., vol. 26, nº 6, p. 701 - 714, 2002.

13. Z. L. Krougly, I. F. Creed, et D. A. Stanford, « A stochastic model for generating disturbance patterns within landscapes », Comput. Geosci., vol. 35, n 7, p. 1451 - 1459, 2009.

14. B. P. Zeigler, R. Jammalamadaka, et S. R. Akerkar, "Continuity and Change (Activity) Are Fundamentally Related in DEVS Simulation of Continuous Systems », in Proceedings of AIS 2004, p. 1-13.

15. F. Qiu et X. Hu, «Spatial activity-based modeling for pedestrian crowd simulation », Simulation, vol. 89, $\mathrm{n}^{\mathrm{o}} 4$, p. 451-465, 2013.

16. J.-S. Bolduc et $\mathrm{H}$. Vangheluwe, «A modeling and simulation package for classic hierarchical DEVS », MSDL Sch. Comput. McGill Univ. Tech. Rep., 2002.

17. R.Franceschini, Paul-Antoine Bisgambiglia, Paul Bisgambiglia, et David R. C. Hill. 2014. « DEVS-Ruby: a Domain Specific Language for DEVS Modeling and Simulation (WIP) ». In CD Proceedings of the Symposium on Theory of Modeling \& Simulation - DEVS Integrative M\&S Symposium. DEVS 14. Tampa, FL, USA: SCS.

18. G. Wainer, et N. Giambiasi. 2001. «Application of the Cell-DEVS Paradigm for Cell Spaces Modelling and Simulation ». SIMULATION 76 (1): 22-39. doi:10.1177/003754970107600102.

19. Fox Jr, W. W. (1970). An exponential surplus-yield model for optimizing exploited fish populations. Transactions of the American Fisheries Society, 99(1), 80-88.

20. Pella, J. J., \& Tomlinson, P. K. (1969). A generalized stock production model. InterAmerican Tropical Tuna Commission Bulletin, 13(3), p. 416-497.

21. Duboz, R., Versmisse, D., Quesnel, G., Muzy, A., \& Ramat, E. (2006). Specification of dynamic structure discrete event multiagent systems. In proceedings of SCS summer simulation 2006, SIMULATION SERIES, 38(2), 103. 